\title{
Procalcitonin as an Early Predictor of Septic Complications after Elective Colon Surgery: A Comparative Study versus Interleukin-6 and C-reactive Protein
}

\author{
Mahasen Abdel Sattar MD, Fouad E. El-Debaky MD, Mosad M. Odah \\ MD, Mahmoud Al-Gamal MD* \& Hamdy Eliwa MD** \\ Departments of Medical Biochemistry, General Surgery* \& Anesthesia \\ and Intensive Care** Faculty of Medicine, Benha University
}

\begin{abstract}
This study aimed to assess the utility of estimation of plasma Procalcitonin (PCT) and serum interleukin-6 (IL-6) and C-reactive protein (CRP), as early (within $24 \mathrm{~h}$ after surgery) predictors of postoperative septic complications in patients who underwent elective colonic resection for malignant disease. The study included 40 patients and 10 healthy subjects as controls for the preoperative values. Patients were observed at ICU for their first 5 postoperative days for the development of systemic inflammatory response syndrome (SIRS), sepsis, severe sepsis or septic shock that were defined according to Bone's criteria. Patients were allocated into 3 groups on the basis of signs of sepsis: Group A (No SIRS/Sepsis), Group B (SIRS) and Group C (Sepsis) group. Blood samples were obtained the day before surgery (Day-0) and at the morning of the first postoperative day (Day-1) for estimation of serum CRP and IL-6 and plasma PCT. Eight patients developed SIRS and 9 patients progressed to sepsis with a total morbidity rate of $42.5 \%$. One patient developed septic shock and died with a mortality rate of 2.5\%. Day-0 serum CRP and plasma PCT showed nonsignificant difference, while Day-0 serum IL-6 was significantly higher compared to control levels. However, Day-1 levels of the three parameters were significantly higher compared to their Day-0 levels. Day-1 serum levels of CRP showed nonsignificant difference between the three study groups; however, Day-1 serum IL-6 was non-significantly higher in group $B$ but was significantly higher in group $C$ compared to its levels in group A with a non-significant increase in group $C$ compared to group B. Day-1 plasma levels of PCT were significantly higher in groups $B$ and $C$ compared to its levels in group $A$ with a significant increase in group $C$ compared to group $B$. There was a positive significant correlation between the frequency of occurrence of SIRS and/or septic complication with levels of serum IL-6 and of plasma PCT, while the correlation was positive non-significant with serum CRP levels and ROC curve analysis showed that plasma PCT levels were highly specific $(A U C=0.928)$, followed by serum levels of IL-6 $(A U C=0.763)$ and serum $C R P$ was the least specific parameter $(A U C=0.498)$. It could be concluded that PCT can be used as a reliable diagnostic parameter to detect and to monitor infectious complications in the postoperative period after colonic surgery and can be detected before the occurrence of clinical infection, especially in patients suspected to be at higher risk for development of SIRS or septic complications.
\end{abstract}




\section{INTRODUCTION}

Procalcitonin, the precursor molecule of calcitonin, is a 116amino acid, $13 \mathrm{kDa}$ peptide that is devoid of known hormonal activity. PCT is produced by the C-cells of the thyroid gland and normally all PCT is intracellularly cleaved into calcitonin, katacalcin, and an N-terminal residue and none is released into the blood stream $^{(\mathbf{1})}$. Serum PCT levels increase dramatically and quickly after a single endotoxin injection. This type of response to a bacterial stimulus makes PCT a potentially sensitive marker for severe bacterial infection ${ }^{(2)}$.

In humans, serum levels of PCT are very low in healthy individuals, however, its serum levels rise during bacterial infections but not during viral infections or inflammatory reactions of noninfectious origin ${ }^{(3)}$. In pulmonary injury and pulmonary infection, the circulating concentrations of procalcitonin and other calcitonin precursors increase rapidly, probably in response to sepsis-related cytokine release from pulmonary neuroendocrine cells of the bronchial epithelium and/or mononuclear cells ${ }^{(4)}$. However, the exact origin of PCT during sepsis is uncertain; it is probably produced by extra-thyroid tissues as evidenced by the observation that patients who have previously undergone total thyroidectomy still produce high levels of PCT during severe infection $^{(5)}$.

Anastomotic leak and intraabdominal sepsis is a serious complication following colorectal surgery. Anastomotic leak can be so devastating that it creates obvious signs of peritonitis that requires an emergency laparotomy; but some cases of anastomotic leak can produce no ill effects and are only detected by radiological studies or direct digital examination and require observation only. However in the middle ground there are patients who suffer serious intraabdominal sepsis and yet the clinical symptoms and signs may be confusing or misleading, particularly in the elderly or immunosuppressed ${ }^{(\mathbf{6})}$. Typically clinical features of anastomotic leak appear around day 5 postoperatively when ischemia of the bowel ends at the anastomosis leads to tissue necrosis, which allows a perforation to occur. At this time, abdominal signs can be minimal although distention and at least mild tenderness are common ${ }^{(7)}$.

Despite the therapeutic advances, both medical and surgical, have improved early postoperative outcome; certain patients remain at high risk of infection and the morbidity and mortality. During the postoperative period sepsis can be difficult to distinguish from other noninfectious situations, such as postoperative systemic inflammatory response syndrome, related to surgical trauma. SIRS can be self-limiting or may progress to severe sepsis or septic shock $^{(8)}$.

It is therefore imperative that early diagnosis and treatment of septic patients may greatly improve outcome. Considering the difficulties in diagnosis of infection and identification of postoperative patients at high risk of dying early after intensive care unit (ICU) admission, an early sensitive and specific marker for SIRS or infection would be of 
interest and may help in determining therapeutic interventions or further diagnostic procedures that could have an impact on patients' outcome ${ }^{(9)}$.

Thus, this study aimed to assess the utility of estimation of plasma PCT and serum IL-6 and CRP, as useful early (within $24 \mathrm{~h}$ after surgery) predictors of postoperative septic complications in patients who underwent elective colonic resection for malignant disease.

\section{PATIENTS \& METHODS}

This prospective study was conducted in General Surgery, Anesthesia at Benha University Hospital and Medical Biochemistry Department, Faculty of Medicine, Benha University. After obtaining the informed patients' consent, 40 consecutive patients assigned to undergo elective colonic resection for malignant diseases were enrolled in the study. Preoperative assessment included physical examination and colon evaluation, including colonoscopy and biopsy taking for histopathological grading.

The preoperative exclusion factors were: age $<18 \mathrm{yr}$, advanced local or metastatic disease, acute bowel obstruction or perforation from cancer, and severe medical illness. Inflammatory bowel disease, familial polyposis, pregnancy, or concurrent or previous malignant tumor, preoperative anti-inflammatory drugs, preoperative infection or treatment with corticosteroids and immunosuppressive illness other than neoplasm also precluded enrollment. The study also included 10 healthy subjects with cross-matched age and sex used as controls for the preoperative values.

All surgeries were performed under general endotracheal anesthesia; during the intra- and postoperative period standard monitoring for all patients was conducted. All patients received $3^{\text {rd }}$ generation cephalosporin as antibiotic prophylaxis after induction of anesthesia and was continued postoperatively to guard against development of infection. Fluid therapy was adjusted to maintain urine output of $0.5-1 \mathrm{cc} / \mathrm{min}$ to assure good tissue perfusion and to guard against development of pulmonary edema and/or congestive heart failure.

Patients were evaluated daily throughout their stay in the ICU for the development of SIRS, sepsis, severe sepsis or septic shock. The definition of these complications was dependent on Bone's criteria $^{(\mathbf{1 0})}$. Patients were allocated into 3 groups on the basis of signs of sepsis: Group A, No SIRS/Sepsis (smooth postoperative course without signs of SIRS or evidence of sepsis), Group B, SIRS group (signs of SIRS or no evidence of sepsis) and Group C, sepsis group (sepsis or severe sepsis or septic shock).

\section{Methods}

\section{Blood sampling:}

Blood samples were obtained the day before surgery (Day-0) and on the morning of the first postoperative day (Day-1). Collected blood samples were divided into two parts one in EDTA containing tube and the other was allowed to clot then serum was separated by centrifugation at 3000 rotation per minute for $10 \mathrm{~min}$. Serum was separated, divided into 2 parts: the 
first for determination of serum level of CRP and the second part was placed in pyrogen-free Eppendorf tubes and stored at $-80^{\circ} \mathrm{C}$ until assayed (within one month).

\section{Investigations}

1-Serum CRP level was estimated using a turbidimetric method ${ }^{(11)}$.

2-Serum IL-6 was measured with an ELISA kit from Pelikine ${ }^{\mathrm{TM}}$ Inc., Concord, USA ${ }^{\mathbf{( 1 2 )}}$.

3-EDTA-plasma specimens were used for estimation of PCT by a competitive radio-immnnoassay method, $5 \mathrm{ml}$ blood samples were collected using chilled syringes and were transferred into polypropylene tubes containing EDTA $(1 \mathrm{mg} / \mathrm{ml}$ of blood) and Aprotinin (a proteinase inhibitor used to preserve the small peptide in the sample $(500 \mathrm{KIU} / \mathrm{ml}$ of blood) at $0^{\circ} \mathrm{C}$. Blood was centrifuged at $1600 \mathrm{~g}$ for 15 minutes at $0^{\circ} \mathrm{C}$. Plasma was separated and stored at $-80^{\circ} \mathrm{C}$ till time of analysis. Extraction procedure was performed using SEP-COLUMN and $1 \%$ trifluroacetic acid (TFA, HPLC Grade) in distilled water, and $60 \%$ acetonitrile (HPLC Grade) in 1\% TFA in distilled water. The upper limit of normal was $0.5 \mathrm{ng}^{(\mathbf{1 3 )}}$.

\section{Statistical analysis}

Obtained data were presented as mean \pm SE, ranges, numbers and ratios. Results were analyzed using paired ttest and Chi-square test. Possible relationships were investigated using Pearson linear regression. Sensitivity \& specificity of CRP, IL-6 and PCT as predictors for development of SIRS and/or sepsis were evaluated using the receiver operating characteristic (ROC) curve analysis judged by the area under the curve (AUC). Statistical analysis was conducted using the SPSS (Version 10, 2002) for Windows statistical package. $\mathrm{P}$ value $<0.05$ was considered statistically significant.

\section{RESULTS}

The study included 40 patients; 18 males and 22 females with a mean age of 56.6 \pm 8 ; range: $46-78$ years and 10 controls; 5 males and 5 females with a mean age of 52.2 \pm 5.9 ; range: 43-62. There was a non-significant difference between patients and controls as regards age and sex distribution. There were 14 right (35\%), 9 left (22.5\%) and 7 transverse (17.5\%) colonic lesions and 10 lesions (25\%) in the rectosigmoid colon. Preoperative histopathological examination of colonoscopic biopsy detected 30 typical adenocarcinomas and 10 mucinous adenocarcinoma (Table 1).

All patients passed smooth intraoperative course with no intraoperative complications and were admitted to post-anesthetic recovery room for follow-up for development of SIRS or sepsis for 5 days; 22 patients passed smooth postoperative course without the development of SIRS or sepsis and included in group $A$ and discharged off the recovery room on the $5^{\text {th }}$ postoperative day to complete their follow-up at surgical ward. Eight patients developed SIRS manifested clinically as fever approaching $39^{\circ} \mathrm{C}$ associated with tachycardia and tachypenia, no patient required mechanical ventilation; 3 of these patients had wound infection that required drainage in only one, 
another 3 patients had mild upper respiratory tract infection and 2 patients had thrombophlebitis, (Group B).

Sepsis was reported in 10 patients (Group C); 6 patients had fever, tachycardia and tachypenia, 2 patients had severe wound infection that required wound drainage and frequent local dressings, 2 had chest infection but did not require mechanical ventilation and 2 patients had pyelitis associated with bacteruria. Three patients developed severe sepsis; one had wound dehiscence and required local management to be prepared for re-admission to the theater for wound debridement and application of secondary sutures, but in the other 2 patients, CT examination detected localized pelvic peritonitis that was managed conservatively in one and the other had anastomotic line dehiscence and localized peritonitis and was re-admitted to the theater for drainage and creation of palliative proximal colostomy. One patient developed septic shock secondary to development of pneumonia and required mechanical ventilation but unfortunately developed acute renal failure on the $6^{\text {th }}$ postoperative day and died on the $8^{\text {th }}$ postoperative day, (Table 2). Thus, 8 patients developed SIRS and 9 patients progressed to sepsis with a total morbidity rate of $42.5 \%$. One patient developed septic shock and died with a mortality rate of $2.5 \%$,

Preoperative (Day-0) serum CRP and plasma PCT showed nonsignificant difference $\left(\mathrm{P}_{1}>0.05\right)$, while preoperative serum IL-6 was significantly higher $\left(\mathrm{P}_{1}<0.01\right)$ compared to control levels. On the other hand, Day-1 levels of the three parameters were significantly higher compared to their Day-0 levels, $\left(\mathrm{P}_{2}<0.001,=0.006 \&=0.001\right.$, for the three parameters, respectively). Day-1 serum levels of CRP were significantly higher in the three groups $\left(\mathrm{P}_{2}<0.001,=0.002 \&=0.005\right.$, respectively) compared to their Day-0 levels with a non-significant intergroup difference between Day-1 serum CRP levels, ( $\left.\mathrm{P}_{3} \& \mathrm{P}_{4}>0.05\right)$. Day-1 serum levels of IL-6 were significantly higher in the three groups $\left(\mathrm{P}_{2}=0.01\right.$ in groups $\mathrm{A} \& \mathrm{~B}$ and $=0.004$ in group $C$ ) compared to their Day-0 levels; however, Day-1 serum IL-6 was non-significantly $\left(\mathrm{P}_{3}>0.05\right)$ higher in group $\mathrm{B}$ but was significantly $\left(\mathrm{P}_{3}<0.05\right)$ higher in group $\mathrm{C}$ compared to its levels in group $\mathrm{A}$ with a non-significant increase of Day-1 serum IL-6 levels in group $\mathrm{C}$ compared to group $\mathrm{B}, \quad\left(\mathrm{P}_{4}>0.05\right)$. Moreover, Day-1 plasma levels of PCT were significantly higher in the three groups $\left(\mathrm{P}_{2}=0.001,0.019\right.$ \& 0.003 in the three groups, respectively) compared to their Day-0 levels; also, Day-1 plasma PCT levels were significantly higher in groups $\mathrm{B}$ and $\mathrm{C}, \quad\left(\mathrm{P}_{3}=0.003 \quad \& \quad<0.001\right.$, respectively) compared to its levels in group A with a significant increase of Day-1 plasma PCT levels in group C compared to group $\mathrm{B}, \quad\left(\mathrm{P}_{4}=0.01\right)$, (Table 3, Fig 1-3).

There was a positive significant correlation between the frequency of occurrence of SIRS and levels of serum IL-6 $(r=0.379, p=0.016)$ and of plasma PCT $\quad(\mathrm{r}=0.618, \quad \mathrm{p}<0.001)$. Moreover, there was a positive significant correlation between the frequency of occurrence of septic 
complication and the levels of serum IL-6 $(r=0.466, \quad p=0.002)$ and of plasma PCT, $(\mathrm{r}=0.651, \quad \mathrm{p}<0.001)$. However, serum CRP showed a positive non-significant correlation with the frequency of occurrence of either SIRS $(\mathrm{r}=0.107, \mathrm{p}>0.05)$ or sepsis, ( $r=0.182, p>0.05$ ), (Table 4).

Analysis of the estimated levels of the three parameters using ROC curve analysis to determine their specificity and sensitivity when estimated on Day-1 after surgery for the prediction of the occurrence of SIRS or septic complications within the immediate postoperative period showed that plasma PCT levels were highly specific with AUC $=0.928$ and 0.930 for SIRS and sepsis, respectively, followed by serum levels of IL-6 with AUC=0.763 and 0.777, respectively and serum CRP was the least specific parameter with AUC $=0.498$ and 0.533 , respectively, (Table 5, Fig. 4\&5).

Table (1): Patients' distribution according to site and histopathological type of colonic lesion

\begin{tabular}{|l|l|c|}
\hline \multirow{3}{*}{ Site of lesion } & Right colon & $14(35 \%)$ \\
\cline { 2 - 3 } & Left colon & $9(22.5 \%)$ \\
\cline { 2 - 3 } & Transverse colon & $7(17.5 \%)$ \\
\cline { 2 - 3 } & Rectosigmoid colon & $10(25 \%)$ \\
\hline Histopathology & Typical adenocarcinoma & $30(75 \%)$ \\
\cline { 2 - 3 } & Mucinous adenocarcinoma & $10(25 \%)$ \\
\hline
\end{tabular}

Data are presented as number and percentages in parenthesis

Table (2): Immediate postoperative data

\begin{tabular}{|l|l|c|}
\hline Variable & Number (\%) \\
\hline No SIRS or sepsis (Group A) & $22(55 \%)$ \\
\hline SIRS (Group B) & Total & $8(20 \%)$ \\
\cline { 2 - 3 } & Wound infection & $3(7.5 \%)$ \\
\cline { 2 - 3 } & Upper respiratory tract infection & $3(7.5 \%)$ \\
\cline { 2 - 3 } & Thrombophlebitis & $2(5 \%)$ \\
\hline Sepsis (Group C) & Total & $10(25 \%)$ \\
\cline { 2 - 3 } & Severe wound infection & $2(5 \%)$ \\
\cline { 2 - 3 } & Chest infection & $2(5 \%)$ \\
\cline { 2 - 3 } & Pyelitis & $2(5 \%)$ \\
\cline { 2 - 3 } & Wound dehiscence & $1(2.5 \%)$ \\
\cline { 2 - 3 } & Pelvic peritonitis & $1(2.5 \%)$ \\
\cline { 2 - 3 } & Dehiscence of anastomosis \& localized peritonitis & $1(2.5 \%)$ \\
\cline { 2 - 3 } & Septic shock 2ry to pneumonia & $1(2.5 \%)$ \\
\hline
\end{tabular}




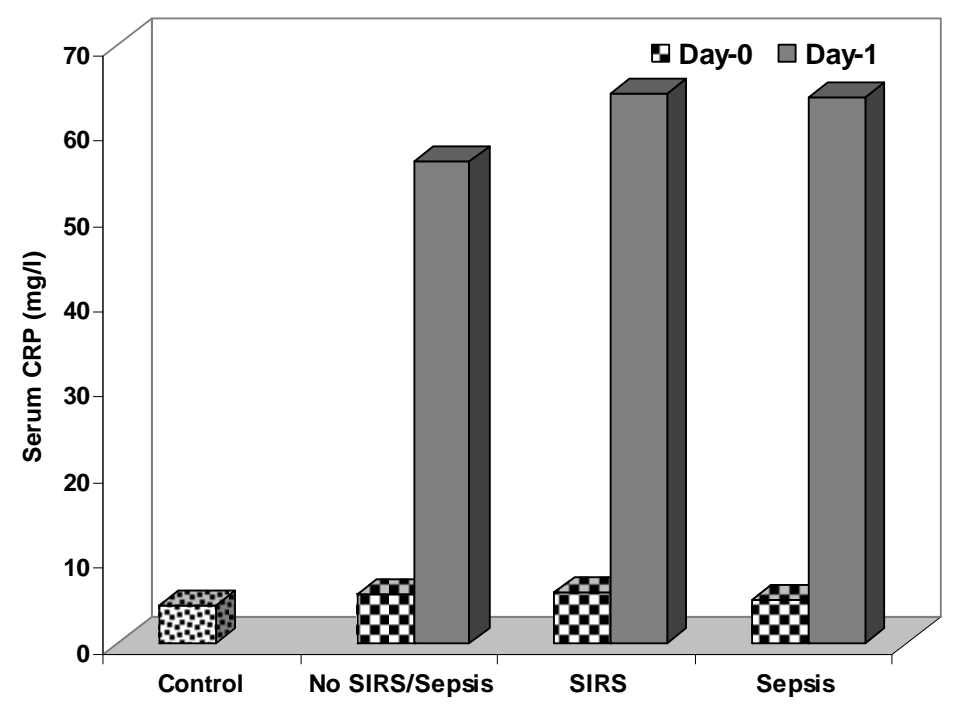

Fig. (1): Serum CRP (mg/l) estimated at Day-0 and Day-1 in patients categorized according to postoperative septic complications compared to control levels

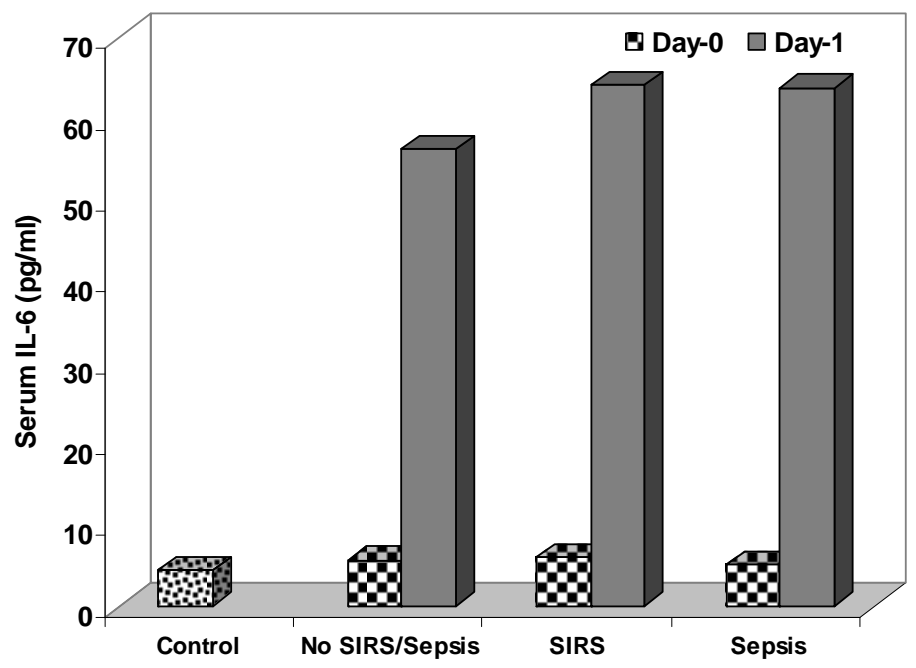

Fig. (1): Serum IL-6 (pg/ml) estimated at Day-0 and Day-1 in patients categorized according to postoperative septic complications compared to control levels 


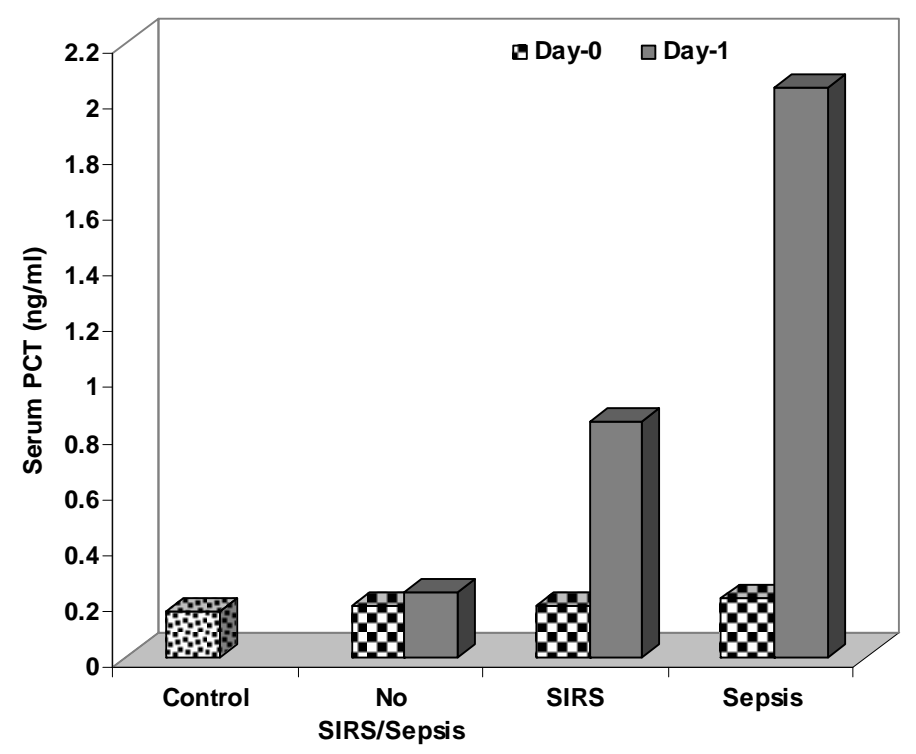

Fig. (3): Serum PCT (ng/ml) estimated at Day-0 and Day-1 in patients categorized according to postoperative septic complications compared to control levels

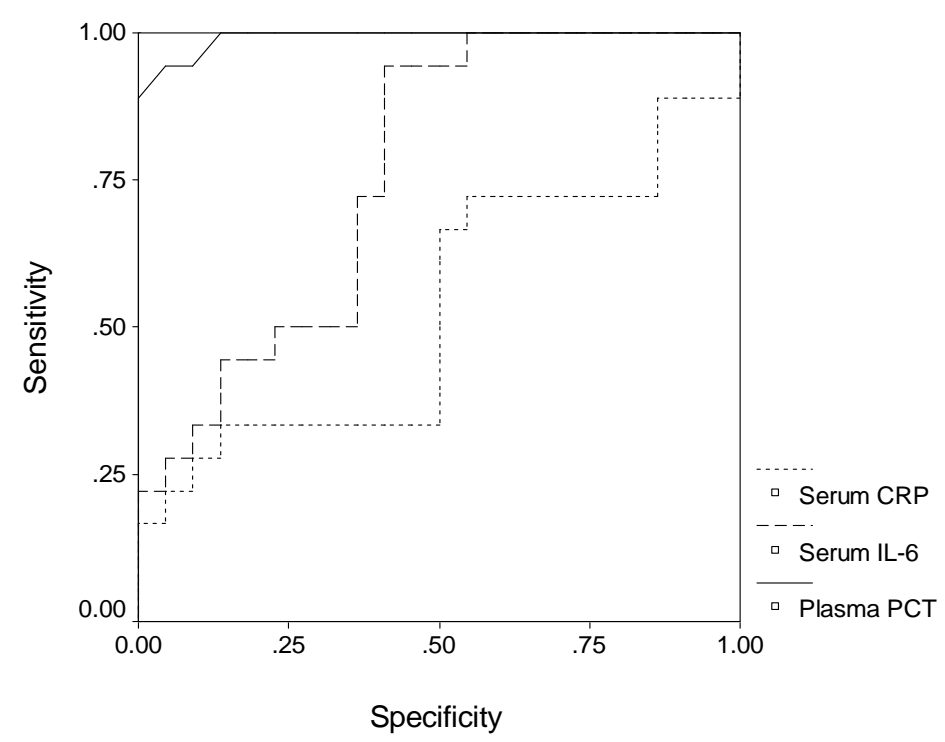

Fig. (4): ROC curve for the specificity of Day-1 estimated levels of serum CRP and IL-6 and plasma PCT as a predictor for occurrence of Day-5 SIRS. 


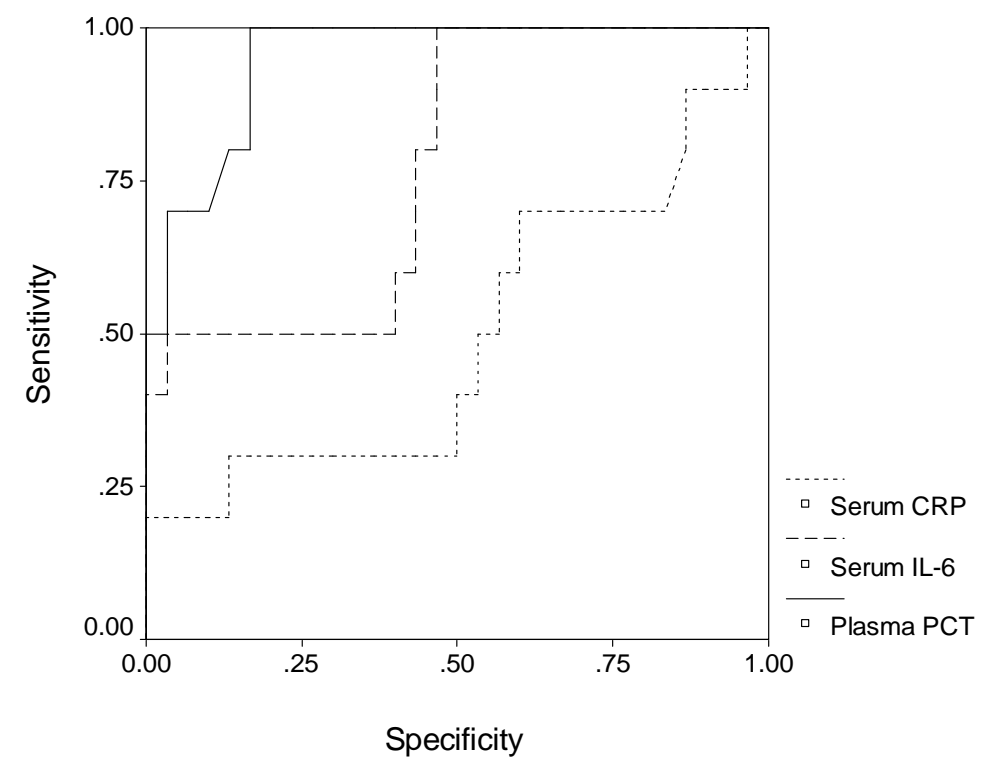

Fig. (5): ROC curve for the specificity of Day-1 estimated levels of serum CRP and IL-6 and plasma PCT as a predictor for occurrence of Day-5 sepsis.

\section{DISCUSSION}

The search for an early molecular marker defining patients at risk for postoperative infections is of great clinical interest because these patients may benefit from intensified monitoring. Thus, this study aimed to assess the utility of PCT, CRP and IL6 as early (within 24 h after surgery) predictors of postoperative morbidity and mortality in patients who underwent colon resection and anastomosis for malignant disease.

All patients were admitted to post-anesthetic recovery room for follow-up for development of SIRS or sepsis for 5 days depending on the previous study of Wagner \& Egger $^{(7)}$ who documented the occurrence of anastomotic dehiscence around day 5 postoperatively.

In the present study one patient developed septic shock and died with a mortality rate of $2.5 \%, 8$ patients developed SIRS and 9 patients progressed to sepsis with a total morbidity rate of $42.5 \%$. These figures go in hand with Testini et al. ${ }^{(6)}$ who reported anastomotic leakage in $6 \%$ with a mortality rate of $1 \%$ in their series of elective colorectal resective surgery. Also, Singh et al. ${ }^{(\mathbf{1 4})}$ who reported intraperitoneal sepsis and clinical anastomotic dehiscence in $1 \%$ and $3 \%$, respectively and 
postoperative mortality rate after elective colorectal cancer surgery of $2 \%$. Moreover, Arch-Ferrer et al. ${ }^{(15)}$ reported that surgical morbidity occurred in $30 \%$ of patients due to wound infections in most cases and mortality rate was $3.6 \%$ with the main cause was sepsis.

Preoperative (Day-0) serum CRP and plasma PCT showed nonsignificant difference $\left(\mathrm{P}_{1}>0.05\right)$, while preoperative serum IL-6 was significantly higher $\left(\mathrm{P}_{1}<0.01\right)$ compared to control levels. Such increased preoperative serum IL-6 levels are in agreement with the results of Nikiteas et al. ${ }^{(\mathbf{1 6})}$ who found median preoperative IL-6 levels were significantly higher in colorectal cancer patients than in normal controls. However, Day-1 levels of the three parameters were significantly higher compared to their Day-0 levels, $\left(\mathrm{P}_{2}<0.001,=0.006 \&\right.$ $=0.001$, for the three parameters, respectively). These findings are in agreement with the previous studies which evaluated surgical impact on cytokine expression and release. BiffI et al., (17) reported that elective surgery induces an increase in circulating IL-6 within 1-3 h, which may remain elevated for 48-72 h in uncomplicated cases as the peak concentration of IL-6 significantly correlated with the operation length and the extent of operative tissue trauma. Angele \& Faist, (18) and Jansen et al. ${ }^{(\mathbf{1 9 )}}$ reported an enhanced secretion of cytokines at different time points after surgery. The increased serum levels of CRP, a primary-phase reactant, signified that surgical procedures are able to activate inflammatory responses and the high levels of CRP could enhance triggering the influx of neutrophils ${ }^{(20)}$ that can release high amounts of IL-6 in response to tissue trauma ${ }^{(21)}$.

Day-1 serum levels of CRP showed non-significant difference between the three study groups; however, Day-1 serum IL-6 was nonsignificantly $\left(\mathrm{P}_{3}>0.05\right)$ higher in group $\mathrm{B}$ but was significantly $\left(\mathrm{P}_{3}<0.05\right)$ higher in group $\mathrm{C}$ compared to its levels in group A with a nonsignificant increase in group $\mathrm{C}$ compared to group $\mathrm{B}\left(\mathrm{P}_{4}>0.05\right)$. On the other hand, Day-1 plasma levels of PCT were significantly higher in groups $\mathrm{B}$ and $\mathrm{C},\left(\mathrm{P}_{3}=0.003 \&<0.001\right.$, respectively) compared to its levels in group A with a significant increase in group $\mathrm{C}$ compared to group $\mathrm{B}$, $\left(\mathrm{P}_{4}=0.01\right)$.

These findings agreed with Mokart et al. ${ }^{(22)}$ who reported that on day 1 after major surgery, PCT and IL-6 levels were significantly higher in patients who developed postoperative septic complications compared to patients free of sepsis but CRP levels were similar. Also, Miyaoka et al. $^{(23)}$ found that IL-6 levels were raised 1 day postoperatively and were higher in the SIRS-matched group compared with the non-SIRS-matched group. Falcoz et al. $^{\text {(24) }}$ found mean value of PCT levels estimated on Day-1 after surgery were significantly higher in patients with postoperative infection than in those with no postoperative infection. Macrina et al., (25) found that serum PCT concentration, one day after coronary artery bypass surgery, increased compared with baseline with the increase in serum PCT concentration being significantly 
greater in patients with a complicated than in patients with uncomplicated postoperative course, while CRP levels were increased significantly compared with baseline in both groups with insignificant difference between both groups.

Moreover, Sarbinowski et al. ${ }^{(26)}$ reported that during the early postoperative period after uncomplicated elective major resection of the large bowel or rectum, SIRS was reflected by the increase in plasma PCT while IL-6, CRP and WBC increased to the same extend in both the SIRS and the non-SIRS group of patients. Bianchi et al. ${ }^{(27)}$ found significant differences in PCT concentrations between patients categorized according to the presence or absence of postoperative complications and reported an inverse correlation between PCT levels and patient outcome.

In support of the obtained results, there was a positive significant correlation between the frequency of occurrence of SIRS and/or septic complication with levels of serum IL6 and of plasma PCT, while the correlation was positive nonsignificant with serum CRP levels and ROC curve analysis showed that plasma PCT levels were highly specific (AUC $=0.928$ ), followed by serum levels of IL-6 (AUC=0.763) and serum CRP was the least specific parameter (AUC=0.498). These findings go in hand with Mitaka ${ }^{(28)}$ who reported that the diagnostic capacity of PCT is superior to that of CRP due to the close correlation between PCT levels and the severity of sepsis and outcome. Also, Aikawa et al. ${ }^{(29)}$ found PCT, endotoxin, IL-6, and CRP concentrations were significantly higher in patients with bacterial infectious disease than in those with nonbacterial infectious disease but the areas under the ROC curve were 0.84 for PCT, 0.60 for endotoxin, 0.77 for IL-6, and 0.78 for CRP for differentiation between both groups. Also, Arkader et al., ${ }^{(30)}$ found that PCT is able to differentiate between SIRS and sepsis while CRP is not with an area under the ROC curve was 0.99 for PCT and 0.54 for CRP.

It could be concluded that PCT can be used as a reliable diagnostic parameter to detect and to monitor infectious complications in the postoperative period after colonic resective surgery and can be detected before the occurrence of clinical infection, especially in patients suspected to be at higher risk for development of SIRS or septic complications

\section{REFERENCES}

1. Florianczyk B (2003): Structure and diagnostic value of procalcitonin. Ann. Univ. Mariae. Curie. Sklodowska [Med]; 58(1):338-42.

2. Gendrel D, Raymond J, Assicot M, Avenel S, Lefevre H, Ravilly $S$, Moulin F, Lacombe C, Palmer $P$, Lebon $P$ \& Bohuon $C$ (1998): Procalcitonin, C-reactive protein and interleukin 6 in bacterial and viral meningitis in children. Presse. Med; 27(23): 1135-9.

3. Wanner GA, Keel M, Steckholzer U, Beier W, Stocker R \& Ertel W (2000): Relationship 
between procalcitonin plasma levels and severity of injury, sepsis, organ failure, and mortality in injured patients. Crit. Care Med.; 28:950-7.

4. Oberhoffer M, Russwurm S, Bredle D, Chatzinicolau K \& Reinhart K (2000): Discriminative power of inflammatory markers for prediction of tumor necrosis factor-f and interleukin-6 in ICU patients with systemic inflammatory response syndrome (SIRS) or sepsis at arbitrary time points. Intensive Care Med.; 26: S170-S174.

5. Wordycki W (2003): Usefulness of plasma procalcitonin (PCT) estimation to diagnose patients in departments of infectious diseases. Przegl Epidemiol; 57(1): 211-9.

6. Testini M, Margari A, Amoruso $M$, Lissidini $G$ \& Bonomo GM (2000): The dehiscence of colorectal anastomoses: the risk factors. Ann. Ital. Chir.; 71(4): 433-40.

7. Wagner OJ \& Egger B (2003): Influential factors in anastomosis healing. Swiss Surg.; 9(3): 10513.

8. Ishikawa M, Nishioka $M$, Hanaki N, Kikutsuji T, Miyauchi T, Kashiwagi $Y$ \& Miki $H$ (2006): Postoperative metabolic and circulatory responses in patients that express SIRS after major digestive surgery. Hepatogastroenterology; 53 (6): 228-33.

9. Dahaba AA, Hagara B, Fall A, Rehak PH, List WF \& Metzler $H$ (2006): Procalcitonin for early prediction of survival outcome in postoperative critically ill patients with severe sepsis. Br. J. Anaesth.; 97(4):503-8.

10. Bone RC, Balk RA, Cerra FB, Dellinger RP, Fein AM, Knaus WA, Schein RM \& Sibbald WJ (1992): American College of Chest Physicians/Society of Critical Care Medicine Consensus Conference. Definitions for sepsis and organ failure and guidelines for the use of innovative therapies in sepsis. Crit Care Med; 20: 86474.

11. Hind CK \& Pepys MB (1986): The role of serum C-reactive protein measurement in clinical practice. Int. Med.; 5: 112-51.

12. Gaines-Das $R E \&$ Poole $S$ (1993): The international standard for interleukin-6-evaluation in an international collaborative study. J. Immunol. Methods.; 160: 147-53.

13. Dwenger A (1984): Radioimmunoassay: An Overview. J. Clin. Biochem.; 22:883

14. Singh KK, Barry MK, Ralston $P$, Henderson MA, McCormick JS, Walls AD, \& Auld CD (1997): Audit of colorectal cancer surgery by non-specialist surgeons. Br. J. Surg.; 84(3):343-7.

15. Arch-Ferrer J, Barreto-Andrade JC, Takahashi T, GarciaOsogobio $S$ \& Leon-Rodriguez $E$ (2001): Surgical treatment of colorectal cancer. 10-year experience at the INCMNSZ. Rev Gastroenterol Mex.; 66(4):18792.

16. Nikiteas NI, Tzanakis N, Gazouli $M$, Rallis $G$, Daniilidis $K$, 
Theodoropoulos G, Kostakis A, Peros G (2005): Serum IL-6, TNF-alpha and CRP levels in Greek colorectal cancer patients: prognostic implications. World J. Gastroenterol.; 11(11):1639-43.

17. Biffl WL, Moore EE, Moore FA \& Peterson VM (1996): Interleukin-6 in the injured patient: marker of injury or mediator of inflammation. Ann. Surg; 224: 647-64.

18. Angele $M K$ \& Faist $E$ (2002): Clinical review: Immunodepression in the surgical patient and increased susceptibility to infection. Critical Care; 6: 298-305

19. Jansen $P L$, Mertens $P R$, Klinge U\& Schumpelick V (2004): The biology of surgical trauma. Surgery; 136(1): 1-4.

20. Chakravortty D \& Kumar KS (1999): Interaction of lipopolysaccharide with human small intestinal lamina propria fibroblast favor neutrophil migration and peripheral blood mononuclear cell adhesion molecules. Biochim. Biophys. Acta.; 1453:261-72.

21. Cassatella MA (1995): The production of cytokines by polymorphonuclear neutrophils. Immunol. Today. 1995; 16:21-26.

22. Mokart D, Leone M, Sannini A, Brun JP, Tison A, Delpero JR, Houvenaeghel G, Blache JL \& Martin C (2005): Predictive perioperative factors for developing severe sepsis after major surgery. Br. J. Anaesth.; 95(6): 776-81.

23. Miyaoka K, Iwase M, Suzuki R, Kondo G, Watanabe $H$, Ito $D$ \&
Nagumo M (2005): Clinical evaluation of circulating interleukin-6 and interleukin-10 levels after surgery-induced inflammation. J. Surg. Res.; 125(2):144-50.

24. Falcoz PE, Laluc $F$, Toubin MM, Puyraveau M, Clement F, Mercier $M$, Chocron $S$ \& Etievent JP (2005): Usefulness of procalcitonin in the early detection of infection after thoracic surgery. Eur. J. Cardiothorac Surg.; 27(6):1074-8.

25. Macrina F, Tritapepe L, Pompei $F$, Sciangula A, Evangelista E, Toscano F, Criniti A, Brancaccio $G$ \& Puddu PE (2005): Procalcitonin is useful whereas C-reactive protein is not, to predict complications following coronary artery bypass surgery. Perfusion.; 20(3):169-75.

26. Sarbinowski $R$, Arvidsson $S$, Tylman $M$, Oresland $T \&$ Bengtsson A (2005): Plasma concentration of procalcitonin and systemic inflammatory response syndrome after colorectal surgery. Acta. Anaesthesiol. Scand.; 49(2):1916.

27. Bianchi RA, Haedo AS \& Romero MC (2006): Role of plasma procalcitonin determination in the postoperative follow-up of cephalic pancreatoduodenectomy. Cir. Esp.; 79(6):356-60.

28. Mitaka C (2005): Clinical laboratory differentiation of infectious versus non-infectious systemic inflammatory response syndrome. Clin. Chim. Acta.; 351(1-2):17-29. 
29. Aikawa N, Fujishima S, Endo S, Sekine I, Kogawa K, Yamamoto Y, Kushimoto S, Yukioka H, Kato N, Totsuka K, Kikuchi K, Ikeda T, Ikeda K, Harada K \& Satomura $S$ (2005): Multicenter prospective study of procalcitonin as an indicator of sepsis. J. Infect. Chemother.; 11(3):152-9.
30. Arkader R, Troster EJ, Lopes $M R$, Junior RR, Carcillo JA, Leone C \& Okay TS (2006): Procalcitonin does discriminate between sepsis and systemic inflammatory response syndrome. Arch Dis. Child.; 91(2):117-20.

\section{استخدام البروكالسيتونين كمؤشر مبكر لحدوث المضاعفات الالتهابية}

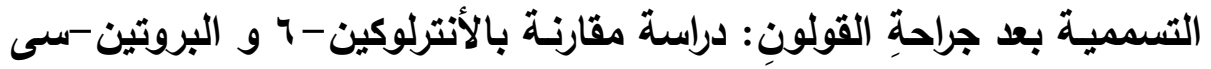
التفاعلى

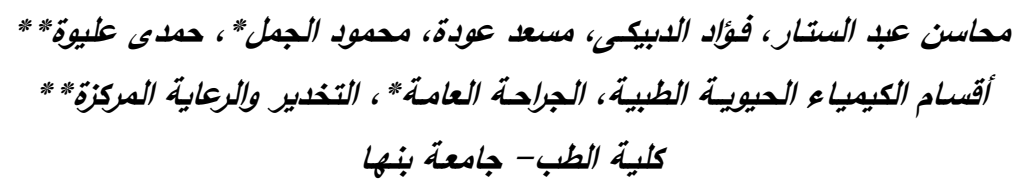


الجراحة. وقد أرتفع مستوى كل من البروكالسيتونين والأنترلوكين-7 بفارق ذو دلالة احصائية فى مرضى دائي

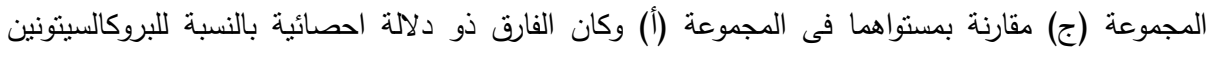

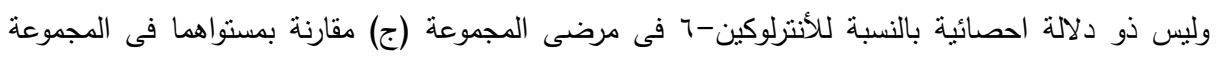

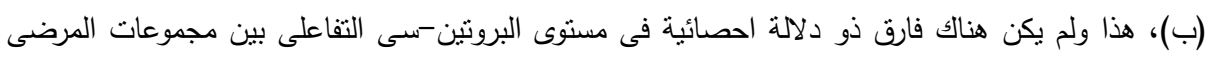

الثناث.

وجد ارتباط ذو دلالة احصائية بين ترددِ حدوثِ متلازمةِ الرَّدّ التحريضيةٍ الثاملةِ، أو المضاعفات

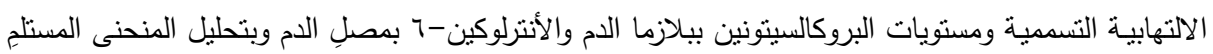

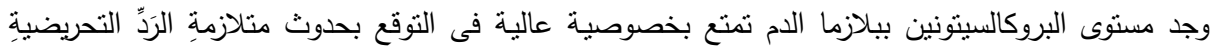

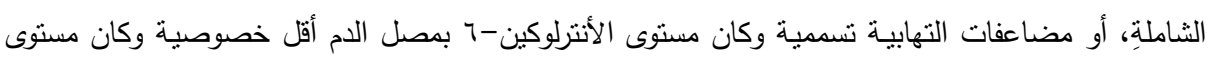

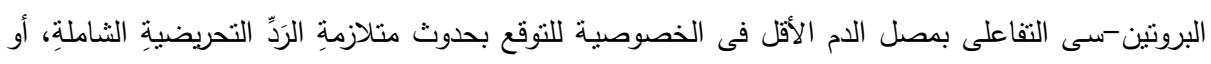
مضاعفات التهابية تسمية.

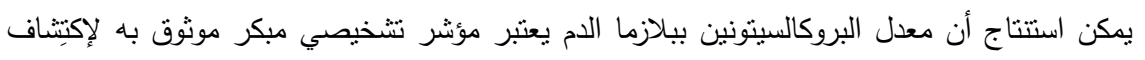

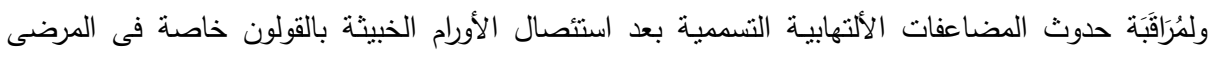

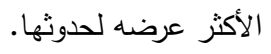

